\title{
Breakout Session
}

\section{Sex/Gender and Racial/Ethnic Disparities in the Care of Osteoporosis and Fragility Fractures}

\author{
Mark D. Neuman MD, Ann M. Kennelly BA, \\ Laura L. Tosi MD
}

Published online: 22 March 2011

(C) The Association of Bone and Joint Surgeons (B) 2011

\begin{abstract}
Background Recent epidemiologic and clinical data suggest men and racial and ethnic minorities may receive lower-quality care for osteoporosis and fragility fractures than female and nonminority patients. The causes of such differences and optimal strategies for their reduction are unknown.

Questions/purposes A panel was convened at the May 2010 American Academy of Orthopaedic Surgeons/ Orthopaedic Research Society/Association of Bone and Joint Surgeons Musculoskeletal Healthcare Disparities Research Symposium to (1) assess current understanding of sex/gender and racial/ethnic disparities in the care of osteoporosis and after fragility fractures, (2) define goals for improving the equity and quality of care, and (3) identify strategies for achieving these goals.

Where are we now? Participants identified shortcomings in the quality of care for osteoporosis and fragility fractures
\end{abstract}

Dr. Tosi serves as a consultant to Amgen Inc (Chesterbrook, PA) and Medtronic Inc (Langhorne, PA). Each author certifies that he or she has no commercial associations (eg, consultancies, stock ownership, equity interest, patent/licensing arrangements, etc) that might pose a conflict of interest in connection with the submitted article.

This work performed at the 2010 AAOS/ORS/ABJS Musculoskeletal Healthcare Disparities Research Symposium, University of Pennsylvania, and Children's National Medical Center.

\section{D. Neuman}

Department of Anesthesiology and Critical Care,

The Leonard Davis Institute for Health Economics,

University of Pennsylvania, Philadelphia, PA, USA

\section{A. M. Kennelly, L. L. Tosi ( $\square)$}

Bone Health Program, Division of Orthopedic Surgery and

Sports Medicine, Children's National Medical Center,

111 Michigan Avenue, Washington, DC 20010, USA

e-mail: 1tosi@cnmc.org among male and minority populations and affirmed a need for novel strategies to improve the quality and equity of care.

Where do we need to go? Participants agreed opportunities exist for health professionals to contribute to improved osteoporosis management and secondary fracture prevention. They agreed on a need to define standards of care and management for osteoporosis and fragility fractures and develop strategies to involve physicians and other health professionals in improving care.

How do we get there? The group proposed strategies to improve the quality and equity of osteoporosis and care after fragility fractures. These included increased patient and physician education, with identification of "champions" for osteoporosis care within and outside of the healthcare workforce; creation of incentives for hospitals and physicians to improve care; and research comparing the effectiveness of approaches to osteoporosis screening and fracture management.

\section{Introduction}

Osteoporosis and associated fragility fractures are a major cause of healthcare utilization [6], disability [19], and excess mortality [4]. Osteoporosis affects approximately 10 million adults in the United States and is a major risk factor for some two million fragility fractures occurring annually in this country. The estimated cost of these fractures exceeded $\$ 17$ billion in 2005 and is projected to rise by $50 \%$ by 2025 because of the rapid increase in the number of older Americans [6]. While major efforts at osteoporosis treatment and fracture prevention have focused on white and Asian women, recent data demonstrate osteoporosis is an emerging public health concern 
among men $[4,6]$ and a range of minority populations in the United States [7, 8, 11]. While the overall incidence of fragility fractures is anticipated to increase by more than $87 \%$ by 2025 , the anticipated increase among minority populations is nearly $175 \%$ [6].

The consequences of fragility fractures in the elderly are profound and are associated with decreases in healthrelated quality of life [10] and increases in functional disability [19, 28]. Fractures of the hip [5, 15] and vertebrae [4] have been associated with pronounced increases in mortality [16]. Compared with white women, ethnic minorities and men experience poorer outcomes after fragility fractures. African Americans are frequently unable to walk at the time of hospital discharge [13] and less likely to walk independently or with help 6 months after fracture [29]. African Americans [17] and men [5, 15] are at greater risk for mortality after hip fracture than white women.

A breakout session at the 2010 American Academy of Orthopaedic Surgeons/Orthopaedic Research Society/ Association of Bone and Joint Surgeons Musculoskeletal Healthcare Disparities Research Symposium, held May 6 to 7, 2010, in Arlington, VA, explored how shortcomings in the quality of osteoporosis care may contribute to these observed differences in fragility fracture outcomes among men and ethnic minorities in the United States. The session had the following three purposes: (1) to assess the current state of understanding of sex/gender and racial/ethnic disparities in care for osteoporosis and fragility fractures, (2) to define goals for future improvement of the equity and quality of care delivered for these conditions, and (3) to identify strategies for achieving these goals. Participants included experts in orthopaedic trauma, bone metabolism, epidemiology, health services research, healthcare disparities, and quality improvement. We summarize the findings of this breakout session.

\section{Where Are We Now?}

Breakout session participants noted a range of evidence suggesting observed differences in osteoporosis-related outcomes among minority patients and men were potentially attributable to variations in the quality of osteoporosis and fragility fracture care delivered to these populations. Decreased bone mineral density increases fracture risk across multiple racial groups [7]; however, rates of screening and treatment for osteoporosis are lower among minorities than among whites, both within populations at risk for osteoporosis [11, 21] and among patients who have already sustained a fracture [20, 26]. Similarly, the hospital treatment of fragility fractures differs among racial groups: African American Medicare beneficiaries receive indicated operative repair for hip fracture at lower rates than comparable white patients [25]. Finally, differences have been documented in the care delivered to male and female patients with osteoporotic fractures, with men being $30 \%$ to $60 \%$ less likely than women to be treated for osteoporosis after hospitalization for an osteoporotic fracture [32].

Participants in the breakout session identified a number of factors that may contribute to shortcomings in the quality of osteoporosis care delivered to ethnic minorities and men. These factors included (1) a lack of awareness among healthcare providers and the public regarding the need for osteoporosis screening and prevention among nonwhite and male patients, (2) lack of financial and nonfinancial incentives to promote osteoporosis screening and treatment for men and women of all ethnic groups, and (3) gaps in knowledge regarding the effectiveness of differing approaches to screening and medical management of osteoporosis, particularly among nonwhite and male patients.

Bone density screening and treatment with calcium, vitamin $\mathrm{D}$, and pharmacologic therapy have the potential to produce health benefits for individuals at risk for osteoporosis and those who have already sustained a fracture $[12,27]$. Additionally, established methods for quantifying fracture risk are demonstrated to predict the likelihood of fracture among both men and women and across racial and ethnic groups [2]. Nonetheless, the group perceived a lack of awareness or concern among medical professionals and the public regarding the underuse of appropriate osteoporosis screening and treatment. Multiple studies in the medical literature support these concerns, documenting underdiagnosis and undertreatment of osteoporosis, among both at-risk individuals without fracture [12, 22, 27] and those who sustained a fragility fracture [18, 31]. While most of these studies have focused on white and Asian women, emerging evidence suggests shortcomings in the diagnosis and treatment of osteoporosis may be most pronounced in racial and ethnic minorities [21] and men [32], even within health systems with high overall rates of screening and treatment of patients at risk for fracture [24].

Participants noted few incentives exist within accreditation, payment, and quality-reporting structures to promote participation by healthcare providers in the longitudinal care of osteoporosis or fragility fractures. Participants commented the lack of a formal system to evaluate the quality of osteoporosis or fragility fracture care delivered by individual physicians may limit the development of incentives for quality improvement targeted at individual providers. Low hospital reimbursement rates for fracture care were also identified as a deterrent to diagnostic testing for underlying causes of secondary osteoporosis, bone density scanning, and initiating pharmacologic treatment for fracture during hospitalization. 
For example, Medicare's Physician Quality Reporting Initiative (PQRI) provides incentive payments to physicians for reporting on selected measures of quality of care; however, participants cited the relatively limited reimbursements available through this program, as well as the small number of PQRI measures focusing on osteoporosis or fracture care, as limiting the effectiveness of this program in improving the care delivered for these conditions.

Overall, participants expressed concern that the limited incentives available for osteoporosis care may reinforce existing gaps in the quality and equity of care delivered for this condition. Further, participants voiced a concern that, without clear incentives for physicians to take ownership of fracture prevention, osteoporosis and postfracture care will likely remain a secondary priority for specialists and generalists alike.

Participants identified multiple gaps in knowledge regarding osteoporosis care that may contribute to variations in care among men and minority patients. For example, minority patients and men have historically been underrepresented in trials of interventions for the prevention of fragility fractures, thereby limiting the evidence base for development of treatment guidelines that target at-risk subgroups [23].

The group expressed concern regarding the limited base of clinical evidence to guide osteoporosis management and postfracture care. Groups such as the National Osteoporosis Foundation have developed consensus documents, such as the Clinician's Guide to Prevention and Treatment of Osteoporosis [23], but there are limited clinical trial data on which to base care strategies, particularly in regard to the evaluation of secondary causes of osteoporosis after fragility fracture. Similarly, the lack of clinical trial data focused on men and minority patients hampers the development of strategies to reduce variations in osteoporosis and postfracture care for these populations. Efforts to standardize postfracture care have produced promising results in primarily white populations [14, 30, 31], but participants agreed on a need for research to define the feasibility of implementing such strategies across diverse patient populations.

\section{Where Do We Need to Go?}

The group agreed increasing the participation of physicians and other healthcare personnel, including physician assistants and advanced practice nurses, in the detection and management of osteoporosis represents a fundamental step toward eliminating disparities in care. Specifically, the group noted opportunities for physicians to incorporate secondary fracture screening and prevention into routine fracture care in both the inpatient and outpatient setting.
The group highlighted the American Orthopaedic Association's "Own the Bone" initiative, a national, Web-based quality improvement program for postfracture care [1] as a means of promoting specialist participation in multidisciplinary care after fragility fracture.

The panel also agreed on the need for incentives targeted at physicians and hospitals to promote participation in quality improvement programs. Participants also noted few data were available regarding promoters and barriers to osteoporosis care among physicians and emphasized such data would be necessary for the creation and dissemination of quality improvement efforts.

The group expressed a need for new models of care delivery to support efforts to improve the quality of osteoporosis care in diverse settings. Participants identified numerous approaches that may ensure ongoing osteoporosis care after treatment of a fragility fracture. Among these is establishing a physician or nonphysician osteoporosis care "champion" within an orthopaedic practice and formalizing mechanisms within physician practices for routine referrals of patients at risk of fracture to specialty physician care, potentially with coordination of care encounters by trained physician extenders. The group expressed a need to evaluate the effectiveness of specific care models, as well as developing a means for promoting adoption of effective strategies across a diverse range of communities and clinical settings.

Since gender and racial disparities in osteoporosis outcomes may reflect lifestyle, behavioral, and economic differences, the group noted improved osteoporosis-related health care would be best viewed as one component of a larger public health effort that would be required to eliminate the identified racial and gender differences in osteoporosis outcomes. As such, the group identified a number of unanswered questions regarding potential patient-level causes of observed outcome differences, regarding the degree to which gaps in awareness of the need for appropriate osteoporosis screening and fracture prevention may exist among men and minority populations and the extent to which such awareness may be increased through broad-based educational campaigns.

\section{How Do We Get There?}

Participants identified three complementary strategies for improving osteoporosis care for men and ethnic minority populations (Table 1), including (1) increased efforts at education of patients and physicians regarding osteoporosis and postfracture care, (2) reform of payment structures to align incentives for high-quality osteoporosis care, and (3) development of an organized research agenda focused on improving the quality and equity of osteoporosis care. 
Table 1. Recommendations for addressing sex/gender and racial/ethnic disparities in osteoporosis screening and treatment proposed in the breakout session

\section{Recommendations}

Targeted educational interventions for patients, families, and healthcare providers

1. Public education campaigns with a focus on men and minorities

2. Development of partnerships between healthcare service providers/professional societies and community-based organizations

3. Pursuit of opportunities to enhance provider knowledge base through existing professional licensure and certification processes

Reform of payment structures to align incentives for high-quality osteoporosis care

1. Expansion of reimbursement policies for physicians to include osteoporosis-related care within the 90 days after a fragility fracture

2. Creation of novel pay-for-reporting or pay-for-performance measures focused on osteoporosis care

3. Identify low-cost bone density screening options to promote self-monitoring in the elderly

Research to identify novel opportunities for intervention.

1. Characterize culturally appropriate models for osteoporosis care delivery

2. Expand clinical investigation regarding strategies for osteoporosis treatment and prevention

3. Evaluation of novel strategies to promote screening for secondary causes of osteoporosis, particularly among populations at high risk for adverse outcomes

Participants voiced a need to create greater public awareness of the importance of osteoporosis care among male and minority populations. Efforts to promote such awareness could include public education campaigns focusing on men and minorities and development of formal partnerships between physician professional societies and community-based organizations to promote further dissemination of educational efforts. The group agreed prior efforts at education among white women regarding osteoporosis have been partially successful in raising public awareness regarding this condition; participants noted public education efforts emphasizing the importance of osteoporosis as a health issue for both men and women of all races may improve interest in prevention and treatment. Further, bone health educational partnerships might be expanded to include places of worship, sports clubs, sporting events, fraternities/fraternal organizations, and reunion planners.

Participants agreed a greater effort must be made to partner with medical accreditation bodies to ensure osteoporosis and fragility fracture care are required areas of competence for healthcare providers. Providers, in turn, must educate patients on how they can help themselves, for example, by informing them of the questions they must be prepared to ask during a healthcare encounter. An extended effort to educate white women on osteoporosis has produced a generation that now knows this disease is a substantial health risk and the patient must share responsibility for its prevention. The participants highlighted a need to extend the same culture of self-help to men and minority populations in the United States.

Participants agreed broad opportunities exist for Medicare and private insurers to alter reimbursement practices to increase incentives for high-quality, equitable osteoporosis care. Suggestions included expanding hospital reimbursement and responsibility for fracture care to include care 90 days after injury to promote evaluation and, where indicated, treatment of secondary causes of osteoporosis. Recognizing incentives have the potential to influence physician behavior, the group agreed expanding the number of PQRI measures for osteoporosis and fragility fracture care and improving reimbursement for reporting have the potential to improve rates of participation among orthopaedists.

Additionally, participants suggested strategies could be pursued to make osteoporosis screening more widespread, as has occurred with monitoring blood pressure and other health parameters. To this end, participants suggested, if prices for bone density testing could be lowered and education regarding fracture risk increased, self-monitoring of fracture risk by seniors may be achieved in community settings.

Beyond research and payment reform, participants agreed on the need for an organized research agenda focused on defining approaches and barriers to initiating osteoporosis prevention and treatment across diverse populations and urged healthcare professional societies to provide leadership in the development of such an agenda. Building on the framework of comparative effectiveness research, the effort "to identify the right treatment for the right patient at the right time" [9], participants indicated such an agenda should seek to identify culturally appropriate, effective models for osteoporosis care delivery, either within existing orthopaedic practices or through integration of emerging approaches to care delivery, such as the patient-centered medical home [3]. Participants emphasized such an agenda should include efforts to expand clinical investigations regarding the prevention and 
treatment of fragility fractures, including the evaluation of secondary causes of osteoporosis, with increased efforts made to focus on male and minority patients.

\section{References}

1. American Orthopaedic Association. Own the Bone. Available at: http://www.ownthebone.org/. Accessed November 1, 2010.

2. Barrett-Connor E, Siris ES, Wehren LE, Miller PD, Abbott TA, Berger ML, Santora AC, Sherwood LM. Osteoporosis and fracture risk in women of different ethnic groups. $J$ Bone Miner Res. 2005;20:185-194.

3. Bitton A, Martin C, Landon BE. A nationwide survey of patient centered medical home demonstration projects. J Gen Intern Med. 2010;25:584-592.

4. Bliuc D, Nguyen ND, Milch VE, Nguyen TV, Eisman JA, Center JR. Mortality risk associated with low-trauma osteoporotic fracture and subsequent fracture in men and women. JAMA. 2009; 301:513-521.

5. Brauer CA, Coca-Perraillon M, Cutler DM, Rosen AB. Incidence and mortality of hip fractures in the United States. JAMA. 2009; 302:1573-1579.

6. Burge R, Dawson-Hughes B, Solomon DH, Wong JB, King A, Tosteson A. Incidence and economic burden of osteoporosisrelated fractures in the United States, 2005-2025. J Bone Miner Res. 2007;22:465-475.

7. Cauley JA, Lui LY, Ensrud KE, Zmuda JM, Stone KL, Hochberg MC, Cummings SR. Bone mineral density and the risk of incident nonspinal fractures in black and white women. JAMA. 2005; 293:2102-2108.

8. Cauley JA, Wu L, Wampler NS, Barnhart JM, Allison M, Chen Z, Jackson R, Robbins J. Clinical risk factors for fractures in multi-ethnic women: The Women's Health Initiative. $J$ Bone Miner Res. 2007;22:1816-1826.

9. Conway PH, Clancy C. Comparative-effectiveness researchimplications of the Federal Coordinating Council's report. $N$ Engl J Med. 2009;361:328-330.

10. Cooper $\mathrm{C}$. The crippling consequences of fractures and their impact on quality of life. Am J Med. 1997;103:12S-17S; discussion $17 \mathrm{~S}-19 \mathrm{~S}$.

11. Curtis JR, McClure LA, Delzell E, Howard VJ, Orwoll E, Saag KG, Safford M, Howard G. Population-based fracture risk assessment and osteoporosis treatment disparities by race and gender. J Gen Intern Med. 2009;24:956-962.

12. Dell R, Greene D, Schelkun SR, Williams K. Osteoporosis disease management: the role of the orthopaedic surgeon. $J$ Bone Joint Surg Am. 2008;90(Suppl 4):188-194.

13. Furstenberg AL, Mezey MD. Differences in outcome between black and white elderly hip fracture patients. J Chronic Dis. 1987;40:931-938.

14. Gardner MJ, Brophy RH, Demetrakopoulos D, Koob J, Hong R, Rana A, Lin JT, Lane JM. Interventions to improve osteoporosis treatment following hip fracture: a prospective, randomized trial. J Bone Joint Surg Am. 2005;87:3-7.

15. Haentjens P, Magaziner J, Colon-Emeric CS, Vanderschueren D, Milisen K, Velkeniers B, Boonen S. Meta-analysis: excess mortality after hip fracture among older women and men. Ann Intern Med. 2010;152:380-390.

16. Ioannidis G, Papaioannou A, Hopman WM, Akhtar-Danesh N, Anastassiades T, Pickard L, Kennedy CC, Prior JC, Olszynski WP, Davison KS, Goltzman D, Thabane L, Gafni A,
Papadimitropoulos EA, Brown JP, Josse RG, Hanley DA, Adachi JD. Relation between fractures and mortality: results from the Canadian Multicentre Osteoporosis Study. CMAJ. 2009;181:265271.

17. Jacobsen SJ, Goldberg J, Miles TP, Brody JA, Stiers W, Rimm AA. Race and sex differences in mortality following fracture of the hip. Am J Public Health. 1992;82:1147-1150.

18. Jennings LA, Auerbach AD, Maselli J, Pekow PS, Lindenauer PK, Lee SJ. Missed opportunities for osteoporosis treatment in patients hospitalized for hip fracture. J Am Geriatr Soc. 2010;58: 650-657.

19. Magaziner J, Hawkes W, Hebel JR, Zimmerman SI, Fox KM, Dolan M, Felsenthal G, Kenzora J. Recovery from hip fracture in eight areas of function. J Gerontol A Biol Sci Med Sci. 2000;55: M498-M507.

20. Mikuls TR, Saag KG, George V, Mudano AS, Banerjee S. Racial disparities in the receipt of osteoporosis related healthcare among community-dwelling older women with arthritis and previous fracture. J Rheumatol. 2005;32:870-875.

21. Miller RG, Ashar BH, Cohen J, Camp M, Coombs C, Johnson E, Schneyer CR. Disparities in osteoporosis screening between atrisk African-American and white women. J Gen Intern Med. 2005;20:847-851.

22. Morris CA, Cabral D, Cheng H, Katz JN, Finkelstein JS, Avorn J, Solomon DH. Patterns of bone mineral density testing: current guidelines, testing rates, and interventions. J Gen Intern Med. 2004;19:783-790.

23. National Osteoporosis Foundation. Clinician's Guide to Prevention and Treatment of Osteoporosis. Washington, DC: National Osteoporosis Foundation; 2010.

24. Navarro RA, Greene DF, Burchette R, Funahashi T, Dell R. Minimizing disparities in osteoporosis care of minorities with an Electronic Medical Record Care Plan. Clin Orthop Relat Res. 2011. DOI Number 10.1007/s11999-011-1852-8.

25. Neuman MD, Fleisher LA, Even-Shoshan O, Mi L, Silber JH. Nonoperative care for hip fracture in the elderly: the influence of race, income, and comorbidities. Med Care. 2010;48:314-320.

26. Neuner JM, Zhang X, Sparapani R, Laud PW, Nattinger AB. Racial and socioeconomic disparities in bone density testing before and after hip fracture. J Gen Intern Med. 2007;22:12391245.

27. Newman ED, Ayoub WT, Starkey RH, Diehl JM, Wood GC. Osteoporosis disease management in a rural health care population: hip fracture reduction and reduced costs in postmenopausal women after 5 years. Osteoporos Int. 2003;14:146-151.

28. Pasco JA, Sanders KM, Hoekstra FM, Henry MJ, Nicholson GC, Kotowicz MA. The human cost of fracture. Osteoporos Int. 2005;16:2046-2052.

29. Penrod JD, Litke A, Hawkes WG, Magaziner J, Doucette JT, Koval KJ, Silberzweig SB, Egol KA, Siu AL. The association of race, gender, and comorbidity with mortality and function after hip fracture. J Gerontol A Biol Sci Med Sci. 2008;63:867872.

30. Rozental TD, Makhni EC, Day CS, Bouxsein ML. Improving evaluation and treatment for osteoporosis following distal radial fractures: a prospective randomized intervention. J Bone Joint Surg Am. 2008;90:953-961.

31. Tosi LL, Gliklich R, Kannan K, Koval KJ. The American Orthopaedic Association's "Own the Bone" initiative to prevent secondary fractures. J Bone Joint Surg Am. 2008;90:163-173.

32. Vik SA, Jantzi M, Poss J, Hirdes J, Hanley DA, Hogan DB, Maxwell CJ. Factors associated with pharmacologic treatment of osteoporosis in an older home care population. J Gerontol A Biol Sci Med Sci. 2007;62:872-878. 